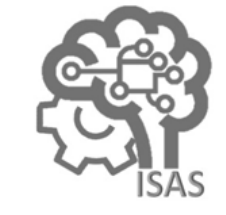

JOURNAL OF APPLIED CIVIL ENGINEERING AND INFRASTRUCTURE TECHNOLOGY (JACEIT)

Vol. 1 No. $2(2020) 14-18$

ISSN Media Elektronik: 2723-5378

\title{
Analisis Produktivitas Tenaga Kerja Pada Pekerjaan Dinding Wallplus Precast Ringan Proyek Perumahan Sekar Jepun Denpasar
}

\author{
Made Sudiarsa ${ }^{1}$, Putu Agus Danes Surya Pratama², Gede Yasada $^{3}$ \\ ${ }^{1}$ Jurusan, Teknik Sipil Politeknik Negeri Bali \\ ${ }^{2} J u r u s a n$ Teknik Sipil Politeknik Negeri Bali \\ ${ }^{3}$ Jurusan Teknik Sipil Politeknik Negeri Bali \\ ${ }^{1}$ sudiarsa@pnb.ac.id*, ${ }^{3}$ gedeyasada@yahoo.com
}

\begin{abstract}
Labor productivity is one of the factors determining the success of a development project of construction services. In measuring the level of labor productivity there are a variety of ways, one of them with the method of time study research was done by observing the level of productivity against 20 workers of the wall plus wall work and accompanied by a questionnaire filling 20 respondents workers. Observations were made during 12 working days. From the results of the collection, questionnaires performed processing with the help of the computer program SPSS (Statistical Package For Social Science) version 23. From the analysis that has been done can note that the magnitude of the productivity the average is $16.41 \mathrm{~m}^{2} /$ days from the calculation of the total cost the implementation of wall work is Rp. 19,773,256.80 and the variable managerial has a dominant influence on the level labor's productivity
\end{abstract}

Keywords: productivity, time study, factor, variable

\begin{abstract}
Abstrak
Produktivitas tenaga kerja adalah salah satu faktor penentu keberhasilan sebuah proyek pembangunan jasa kontruksi. Dalam mengukur tingkat produktivitas tenaga kerja ada berbagai macam cara, salah satunya dengan metode time. Penelitian ini dilakukan dengan cara mengamati tingkat produktivitas terhadap 20 tenaga kerja pekerjaan dinding wallplus dan disertai pengisian kuesioner oleh 20 responden tenaga kerja. Pengamatan dilakukan selama 12 hari kerja. Dari hasil pengumpulan data kuesioner dilakukan proses pengolahan data dengan bantuan computer program SPSS (Statistical Package For Social Science) versi 23. Dari analisis data yang telah dilakukan dapat diketahui bahwa besarnya nilai produktivitas rata rata adalah $16,41 \mathrm{~m}^{2} / \mathrm{Hari}$, dari hasil perhitungan total Biaya Pelaksanaan pekerjaan dinding wallplus sebesar Rp. 19.773.256,80 dan variabel managerial mempunyai pengaruh yang dominan terhadap tingkat produktivitas tenaga kerja.
\end{abstract}

Kata kunci: Produktivitas, Time Study, Faktor, Variabel

Diterima Redaksi : 08-11-2020 | Selesai Revisi : 18-11-2020 | Diterbitkan Online : 04-12-2020

\section{Pendahuluan}

\subsection{Latar Belakang}

Produktivitas pekerja menjadi salah satu faktor penentu keberhasilan suatu proyek. Progress suatu proyek bisa mengalami keterlambatan bila nilai produktivitas rendah, dan sebaliknya produktivitas yang tinggi bisa menjamin ketepatan jadwal. Produktivitas merupakan perbandingan total output berupa barang maupun jasa pada waktu tertentu dibagi dengan total input-nya yang antara lain bisa berupa: man-power, manajemen, material, modal, dan mesin yang dimiliki (Olomolaiye, 1998). Variabel-variabel input tersebut sangat mempengaruhi nilai produktivitas yang dihasilkan [3]. Menurut [2], nilai produktivitas dipengaruhi letak antara material dan tempat pengerjaan, jumlah pekerja, relaxation allowances, material yang digunakan, dan penggunaan alat. Pemilihan material yang tepat dapat menunjang produktivitas suatu proyek. Dewasa ini, muncul berbagai produk material dinding ringan 
dengan spesifikasi yang beragam. Salah satunya produk material dinding yaitu wallplus [8]. Wallplus merupakan precast ringan komposit yang diperkuat fibercement sebagai kulit luar dengan lapisan ini terdiri dari EPS dan beton agregat perpaduan bahan ini membuat wallplus mudah diangkat karena $65 \%$ lebih ringan dibandingkan batu bata konvensional.

Proyek Pembangunan Perumahan Sekar Jepun Denpasar-Bali sebagian besar dindingnya menggunakan material wallplus. Adanya inovasi baru dalam pengerjaan dinding dengan material wallplus, maka penulis tertarik melakukan sebuah penelitian mengenai Analisis Tingkat Produktivitas Tenaga Kerja pada Pekerjaan dinding Wallplus Precast Ringan.

\subsection{Rumusan Masalah}

Berdasarkan latar belakang diatas, rumusan masalah dalam penelitian ini adalah bagaimana produktifitas tenaga kerja dan biaya pelaksanaan serta faktor dominan yang berpengaruh pada pekerjaan pasangan dinding Wallplus pada proyek pembangunan perumahan Sekar Jepun Denpasar.

\subsection{Tujuan Penelitian}

Penelitian ini bertujuan untuk mengetahui tingkat produktifitas tenaga kerja dan biaya pelaksanaan serta faktor dominan yang berpengaruh pada pekerjaan pasangan dinding Wallplus pada proyek pembangunan perumahan Sekar Jepun Denpasar.

\section{Metode Penelitian}

\subsection{Rancangan Penelitian}

Dalam penelitian ini objek yang akan diteliti adalah Proyek Pembangunan Perumahan Sekar Jepun Denpasar. Metode yang digunakan adalah deskriptif observasional, yaitu suatu metode yang meneliti keadaan secara aktual di lapangan secara lengkap dan rinci, meneliti sekelompok manusia, suatu obyek, suatu kelas peristiwa pada masa sekarang. Instrumen penelitian yang digunakan dalam penelitian ini adalah kuesioner, yaitu teknik pengumpulan data melalui pertanyaan kepada responden secara langsung baik individu maupun kelompok.

\subsection{Penentuan Sumber Data}

Dalam penelitian ini, jenis data yang digunakan adalah sebagai berikut: data primer melalui pengamatan, berupa hasil kerja dari volume yang dikerjakan dan jam kerja dari waktu yang diperlukan, jumlah tenaga kerja untuk menyelesaikan pekerjaan. Data-data sekunder berupa: gambar kerja (shop drawing), jadwal proyek (time schedule), RKS (Rencana Kerja dan Syaratsyarat), dan RAB (penawaran kontraktor).

\subsection{Variabel Penelitian}

Pengukuran operasional variabel ini menggunakan teknik skoring. Teknik skoring yang digunakan dalam penelitian ini adalah skala likert yaitu pertanyaanpertanyaan yang memberikan alternatif 4 jawaban dan jawaban ini diberi skor 1,2,3,4. Definisi operasional variabel menjelaskan variabel yang akan digunakan dalam penelitian. Produktivitas tukang sebagai variabel terikat, yang nilainya dipengaruhi oleh satu atau lebih variabel bebas.

\subsection{Tahapan Penelitian}

Adapun tahapan dari peneliyian ini adalah:

Tahap I berupa pengumpulan data dengan langkahlangkah:

1. Suvey lapangan untuk melihat apakah proyek yang ada memenuhi syarat untuk dijadikan lokasi penelitian

2. Melakukan proses perijinan kepada pelaksana atau pemilik proyek

3. Menentukan zona yang akan diamati, pengumpulan data tenaga kerja yang diperlukan untuk mendukung penelitian dengan wawancara langsung

4. Pengumpulan data proyek dengan mendapatkan data berupa gambar kerja (shop drawing), jadwal proyek (time schedule), RKS (Rencana Kerja dan Syarat-syarat), dan RAB (penawaran kontraktor).

5. Perhitungan waktu di lapangan menggunakan perhitungan kumulatif atau pengukuran waktu secara terus-menerus dimana jamnya dimulai pada awal aktivitas pertama dan jam tidak dihentikan hingga seluruh aktivitas selesai. Pembacaan jam pada akhir setiap pekerjaan dicatat dan waktu yang diperlukan diperoleh dengan pengurangan setelah itu. Waktu yang tidak efektif ditemui selama pengamatan, hal itu harus dihitung dan dicatat secara tepat. Waktu tidak efektif ini termasuk istirahat dan relaksasi, memperbaiki kesalahan, mengerjakan pekerjaan yang tidak berkaitan, waktu menganggur atau waktu menunggu yang terjadi karena gangguan seperti menunggu material, menunggu pekerja yang lain, dan lainnya, sehingga waktu yang tidak efisien ini dapat diambil sebagai perhitungan yang berkelanjutan.

6. Pengumpulan data produktivitas melalui observasi langsung di lapangan Data tersebut berupa observe time, observe rating, dan standard rating yang dicatat dalam formulir observasi dengan menggunakan metode time study. Setelah itu data yang didapat akan diolah menjadi standard time, dan juga mencatat volume yang dikerjakan seharinya yang selanjutnya akan digunakan untuk menghitung produktivitas

7. Penyebaran kuesioner melalui daftar pertanyaan dan wawancara terhadap tenaga kerja untuk mendapatkan data diri tenaga kerja dan variabel yang dominan berpengaruh 
8. Melakukan tahap scoring data kuesioner Langkah yang dilakukan dalam tahap ini adalah memberikan scoring terhadap jawaban responden dalam kuesioner

Tahap II berupa analisa data yaitu:

1. Standard Time

Standard time merupakan penjumlahan dari basic time, relaxation allowances dan contingency allowances.

$$
\text { Basic time }=\text { obsv time } \times \frac{\text { obsv.rating }}{\text { std.rating }}
$$

Basic time yang telah didapat melalui rumus diatas, lalu dikalikan dengan jumlah persentasi antara nilai relaxation allowances dan contingency allowances yang didapat melalui pengamatan secara aktual di lapangan untuk mendapatkan nilai standard time

2. Kuantitas Pekerjaan

Merupakan data primer yang memuat volume pekerjaan dan diperoleh dari shop drawing (gambar kerja).

3. Jumlah Pekerja

Merupakan data primer yang diperoleh saat pengamatan dilakukan. Dicatat pada form observasi.

4. Produktivitas

Rumus produktivitas yang digunakan adalah rumus produktivitas dari Dipohusodo (1996) [4], yaitu:

$$
\text { Produktivitas }=\frac{\text { Hasil kerja }}{\text { jam kerja }}
$$

5. Mencari biaya pelaksanaan berupa, Biaya harga upah / pekerja proyek, Biaya peralatan / mesin untuk operasional proyek, Biaya bahan / material bangunan mengacu pada harga proyek pembangunan perumahan sekar jepun berlangsung [5].

6. Uji t (t test)

Uji t ini digunakan untuk menguji apakah variabelvariabel yang ada secara parsial (sendiri-sendiri) benar-benar mempunyai pengaruh signifikan atau tidak signifikan, terhadap kinerja sumber daya manusia dalam pekerjaan pasangan wallplus, yaitu membandingkan antara $\mathrm{t}$ hitung masing-masing variabel dan sig $\mathrm{t}$ dengan nilai tingkat signifikan $\mathrm{t}$ $=5 \%(0,05)$ yang telah ditetapkan. Jika nilai $\mathrm{t}$ hitung lebih besar dari t tabel maka $\mathrm{H}_{0}$ ditolak dan nilai signifikanlebih kecil dari a maka $\mathrm{H}_{0}$ diterima dan nilai signifikan lebih besar dari a maka $\mathrm{H}_{0}$ diterima.

\subsection{Bagan Alir Penelitian}

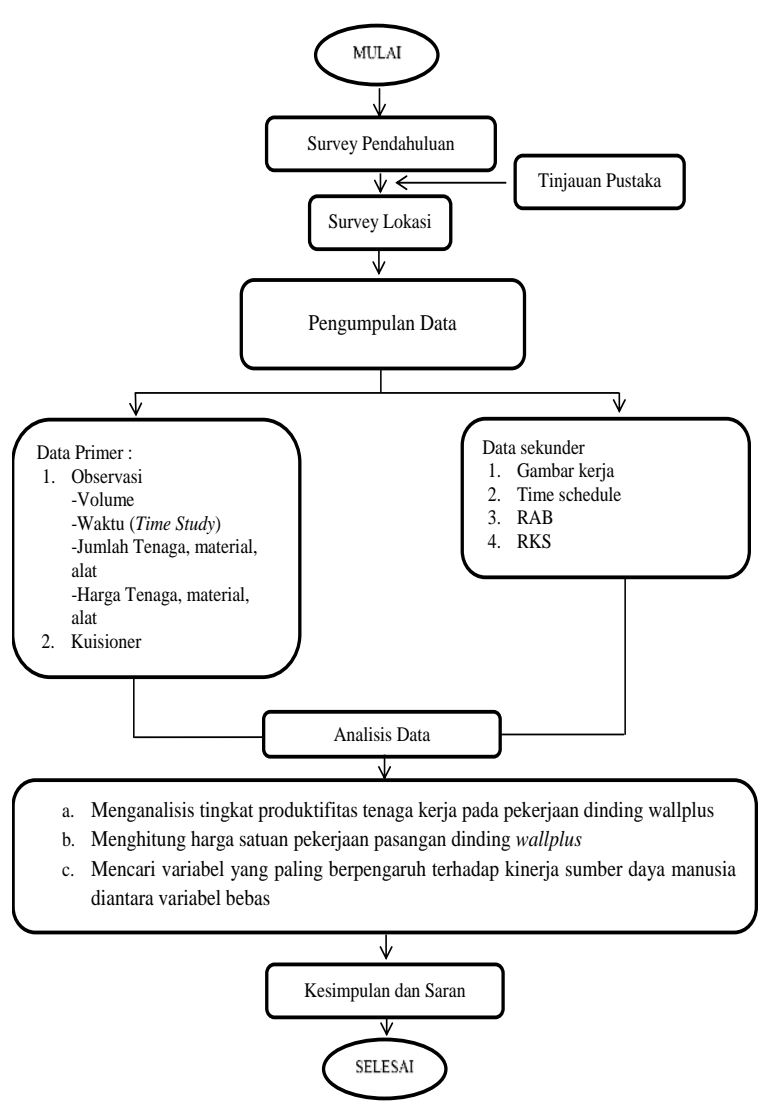

Gambar 2. Bagan Alir Penelitian

\section{Hasil dan Pembahasan}

Tingkat produktivitas tenaga kerja di proyek ditentukan oleh banyak factor. Dalam penelitian ini penulis meninjau 5 faktor dari pribadi tenaga kerja yaitu factor umur, keahlian tenaga kerja, pengalaman kerja, kesehatan tenaga kerja dan managerial [1]. Faktorfaktor tersebut dapat berdiri sendiri dan dapat pula terkombinasi antar faktor.

Penelitian tenaga kerja pada pekerjaan dinding Wallplus Precast Ringan dilakukan selama 2 minggu (12 hari kerja), semua unit didesain dengan satu tipe dengan luas tanah $70 \mathrm{~m}^{2}$ dan luas bangunan $50 \mathrm{~m}^{2}$ [7]. Penelitian dilakukan terhadap 20 orang tenaga kerja dimana setiap satu proyek terdapat 5 orang tenaga kerja, antara lain yaitu, 1 mandor, 1 kepala tukang, 1 tukang, dan 2 pekerja. Dalam sehari pengamatan dilakukan selama 8 jam kerja, Untuk membantu dan memperjelas jawaban dari pertanyaan dilakukan juga wawancara kepada beberapa tenaga kerja yang telah mengisi kuesioner. Pelaksanaan pengumpulan data penelitian dilakukan pada proyek Pembangunan Perumahan Sekar Jepun VI Denpasar Timur, dengan perusahaan pengembang PT Iswa Graha Property. 


\subsection{Waktu Pengamatan}

Perhitungan waktu di lapangan menggunakan perhitungan komulatif atau pengukuran waktu terusmenurus dimana jamnya dimulai pada awal aktivitas pertama bagian pekerjaan dinding wallplus dan dihentikan jika tidak berkaitan dengan pekerjaan dinding wallplus, hal seperti itu akan terus dilakukan dengan mencatat berapa lama waktu yang diperlukan untuk mengerjakan pekerjaan dinding Wallplus dan hasil akhirnya semua catatan waktu tersebut akan dijumlah

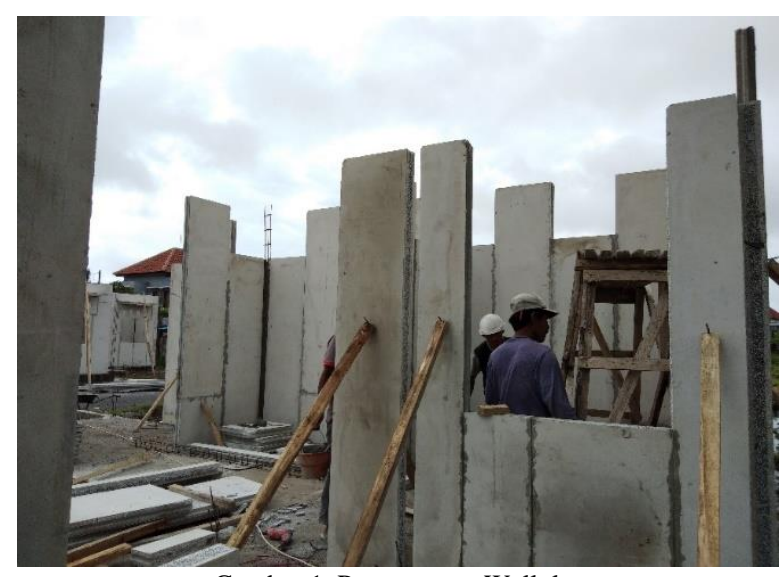

Gambar 1. Pemasangan Wallplus

\subsection{Perhitungan BasicTime}

Basic time tiap pekerjaan dinding wallplus precast ringan diproleh dari observasi lapangan dari tiap pekerjaan. Di dalam observasi lapangan dicatat waktu pengamatan (observe time) dari tiap elemen aktivitas pekerjaan.

Tabel 1. Nilai Basic Time

\begin{tabular}{|c|c|c|c|c|c|c|c|c|}
\hline \multirow{2}{*}{$\begin{array}{l}\text { Jenis Pekerjaan : Dinding } \\
\text { Tanggal } \\
\text { No Observasi }: 9\end{array}$} & \multicolumn{6}{|c|}{ FORM RINGKASAN } \\
\cline { 2 - 8 } & \multicolumn{6}{|c|}{ WAKTU DASAR (BT) } \\
\hline No & ELEMEN EKTIVITAS & 1 & 2 & 3 & 4 & 5 & 6 & $\begin{array}{c}\text { Total } \\
\text { BT }\end{array}$ \\
\hline 1 & $\begin{array}{l}\text { Pemasangan Wallplus dan acian + } \\
\text { Pemasangan Besi angker + set dinding }\end{array}$ & 22.57 & & & & & & 22.57 \\
\hline 2 & Pemasangan Kayu Penguat & 3.96 & & & & & & 3.96 \\
\hline
\end{tabular}

\subsection{Perhitungan Standard Time}

Setelah mendapat nilai basic time maka akan dijumlahkan dengan nilai persentase pengaruh relaxation dan contingency allowance untuk menghitung nilai standard time. Untuk hasil Standard Time tiap observasi seperti terlihat pada Tabel 1 sebagai berikut:
Tabel 2. Nilai Standard Time

\begin{tabular}{clcc}
\hline \multirow{2}{*}{ No Observasi } & Jenis Pekerjaan & $\begin{array}{c}\text { TOTAL BASIC } \\
\text { TIME (Menit) }\end{array}$ & $\begin{array}{c}\text { STANDARD TIME } \\
\text { (Menit) }\end{array}$ \\
\hline 1 & Dinding Wallplus & 60,43 & 111.80 \\
\hline 2 & Dinding Wallplus & 251,44 & 462.99 \\
\hline 3 & Dinding Wallplus & 261,42 & 480.90 \\
\hline 4 & Dinding Wallplus & 210,61 & 385.69 \\
\hline 5 & Dinding Wallplus & 359,89 & 656.45 \\
\hline 6 & Dinding Wallplus & 204,60 & 374.61 \\
\hline 7 & Dinding Wallplus & 241,00 & 422.66 \\
\hline 8 & Dinding Wallplus & 225,59 & 449.69 \\
\hline 9 & Dinding Wallplus & 26,53 & 49.56 \\
\hline 10 & Dinding Wallplus & 360,10 & 798.13 \\
\hline 11 & Dinding Wallplus & 261,47 & 476.08 \\
\hline 12 & Dinding Wallplus & 182,51 & 334.62 \\
\hline
\end{tabular}

\subsection{Perhitungan Produktivitas}

Untuk menghitung nilai produktivitas dari pekerjaan Dinding Wallplus kita harus mengetahui hasil kerja (output), kemudian dibagi dengan standar time Untuk hasil Produktivitas tiap observasi seperti terlihat pada tabel 3 sebagai berikut:

Tabel 3. Nilai Produktivitas

\begin{tabular}{clc}
\hline $\begin{array}{c}\text { No } \\
\text { Observasi }\end{array}$ & Jenis Pekerjaan & PRODUKTIVITA: \\
& & $(\mathrm{m} 2 / \mathrm{hari})$ \\
\hline 1 & Dinding Wallplus & 9.09 \\
\hline 2 & Dinding Wallplus & 30.51 \\
\hline 3 & Dinding Wallplus & 22.10 \\
\hline 4 & Dinding Wallplus & 5.97 \\
\hline 5 & Dinding Wallplus & 9.44 \\
\hline 6 & Dinding Wallplus & 11.82 \\
\hline 7 & Dinding Wallplus & 13.41 \\
\hline 8 & Dinding Wallplus & 21.27 \\
\hline 9 & Dinding Wallplus & 14.18 \\
\hline 10 & Dinding Wallplus & 9.08 \\
\hline 11 & Dinding Wallplus & 24.60 \\
\hline 12 & Dinding Wallplus & 25.41 \\
\hline & Rata Rata
\end{tabular}

\subsection{Perhitungan Koefisien Tenaga Kerja}

Besar produktivitas akan dipengaruhi oleh jumlah tenaga kerja yang digunakan. Semakin banyak pekerja akan menghasilkan produktivitas semakin besar. Namun, harus disesuaikan dengan data yang telah ada agar jumlah pekerja tidak berlebihan dan menyebabkan pekerja tidak produktif.

Setelah nilai produktivitas diketahui, kemudian koefisien tenaga kerja dapat dicari dengan data berupa jumlah tenaga kerja, dan produktivitas tenga kerja tersebut.

Koefisien tenga kerja dapat dicari dengan rumus.

Koefisien Pekerja = P/Qt

Koefisien Tukang $=\mathrm{T} / \mathrm{Qt}$

Koefisien Kepala Tukang $=\mathrm{KT} / \mathrm{Qt}$

Koefisien Mandor $=\mathrm{M} / \mathrm{Qt}$ 
Berikut adalah perhitungan koefisien Tenaga Kerja pekerjaan dinding wallplus precast ringan sebagai berikut:

Kelompok pekerja yaitu 5 Orang Antara lain:

$\begin{array}{ll}\text { Mandor } & : 1 \text { orang } \\ \text { Kepala Tukang Batu } & : 1 \text { orang } \\ \text { Tukang Batu } & : 1 \text { orang } \\ \text { Pekerja } & : 2 \text { orang }\end{array}$

Koefisien Mandor $=\frac{0,3}{16,41}$

Jadi $=0,018$

Koefisien Kepala Tukang Batu $=\frac{0,5}{16,41}$

Jadi $=0,031$

Koefisien Tukang Batu $=\frac{1}{16,41}$

Jadi $=0,061$

Koefisien Pekerja $=\frac{2}{14.17}$

Jadi $=0,141 \mathrm{OH}$

Keterangan :

Tk = Jumlah Jam kerja per hari (8 jam)

$\mathrm{P} \quad$ = Jumlah pekerja yang diperlukan (1 orang)

$\mathrm{T} \quad=$ Jumlah tukang yang diperlukan (1 orang)

$\mathrm{KT}=$ Jumlah kepala tukang yang diperlukan $(0,5$ orang) dikarenakan keterlibatan mandor $50 \%$ dari pekerjaan dinding wallplus precast ringan

M = Jumlah mandor yang diperlukan ( 0,3 orang) dikarenakan keterlibatan mandor $50 \%$ dari pekerjaan dinding wallplus precast ringan

QT = Rata-rata Produktivitas tenaga kerja

Nilai hasil produktivitas massing-masing tenaga kerja yaitu Mandor : 0,018 Kepala Tukang Batu : 0,031 Tukang Batu : 0,061 Pekerja : 0,141. Hasil observasi bisa dilihat pada tabel 4. dibawah sebagai berikut:

Tabel 4. Nilai Koefisien Tenaga Kerja

\begin{tabular}{lll}
\hline \multicolumn{1}{c}{ URAIAN } & SATUAN & KOEFISIEN \\
\hline TENAGA & & \\
\hline Pekerja & OH & 0.141 \\
\hline Tukang batu & OH & 0.061 \\
\hline Kepala Tukang & OH & 0.031 \\
\hline Mandor & OH & 0.018 \\
\hline
\end{tabular}

\subsection{Perhitungan Harga Satuan Pekerjaan Dinding Wallplus}

Harga satuan pekerjaan wallplus dipengaruhi oleh angka koefisien yang menunjukan nilai satuan bahan/material, nilai satuan alat, dan nilai satuan upah tenaga kerja ataupun satuan pekerjaan yang dapat digunakan sebagai acuan/penduan untuk merencanakan atau mengendalikan biaya suatu pekerjaan. Untuk harga bahan material didapat dipasaran, yang kemudian dikumpulkan didalam suatu daftar yang dinamakan harga satuan bahan/material, sedangkan upah tenaga kerja didapat dilokasi setempat yang kemudian dikumpulkan didalam suatu daftar yang dinamakan daftar harga satuan upah tenaga kerja. Harga satuan yang didalam perhitungan haruslah disesuaikan dengan kondisi lapangan, kondisi alat/efisiensi, metode pelaksanaan dan jarak angkut.

Adapun perumusan analisa pekerjaan dinding wallplus sebagai berikut:

Upah : Harga Satuan Upah x Koefisien (analisa upah)

Bahan : Harga Satuan Bahan x Koefisien (analisa bahan)

Alat Bantu : Harga Satuan Upah x 20\%

Maka didapat :

Harga Satuan Pekerjaan $=$ Upah + Bahan + Alat

Untuk lebih jelasnya hasil analisa harga satuan pekerjan dinding wallplus bisa dilihat pada tabel 3.4 sebagai berikut:

Tabel 5. Hasil Analisa Harga Satuan Pekerjaan Dinding Wallplus

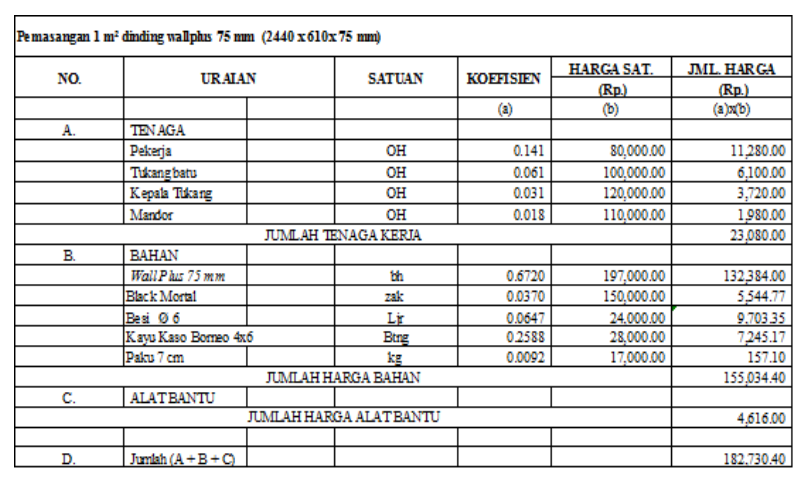

Sehingga total biaya pekerjaan dinding wallplus untuk Type bangunan 50/70 dengan luas dinding 108,21 $\mathrm{m}^{2}$ pada proyek Pembangunan Perumahan Sekar Jepun VI Denpasar yaitu : Rp. 19.773.256,80

\subsection{Analisis Faktor Mempengaruhi Produktivitas}

Besarnya tingkat produktivitas tenaga kerja dipengaruhi oleh adanya variabel-variabel bebas. Untuk mengetahui dari variabel-variabel bebas tersebut telah dilakukan pengolahan data dengan SPSS versi 23 terhadap kuesioner yang telah diisi oleh tenaga kerja. Hasil dari pengujian menunjukan bahwa data kuesioner telah valid dan reliabel, oleh karena itu data layak untuk dilakukan pengujian hipotesis.

Dari hasil pengujian hipotesis yang telah dilakukan terhadap data yang ada, dari hasil uji t diperoleh hasil hipotesis pengaruh dari masing-masing variable secara sendiri sendiri (parsial) terhadap tingkat produktivitas tenaga kerja pekerjaan Dinding Wallplus. Hasil diketahui dengan membandingkan besarnya nilai $t$ dan sig t hitung dengan nilai table yaitu :

a. Variable (X1) Umur Pekerja

Diperoleh sig $=0,000$ dan $\mathrm{t}$ hitung $=4,411>\mathrm{t}$ tabel $=2,093$, dan diperoleh juga $\mathrm{R}$ square 0,519 artinya variable secara varsial memiliki pengaruh yang 
signifikan terhadap variable terikat yaitu produktivitas pekerjaan dengan pekerjaa dinding Wallplus sebesar $51,9 \%$

b. Variable (X2) Keahlian Pekerja

Diperoleh sig $=0,000$ dan $\mathrm{t}$ hitung $=4,302>\mathrm{t}$ tabel 2,093, dan diperoleh juga $\mathrm{R}$ square 0,507 artinya variable secara varsial memiliki pengaruh yang signifikan terhadap variable terikat yaitu produktivitas pekerjaan dengan pekerjaa dinding Wallplus sebesar 50,7\%

c. Variable (X3) Pengalaman Pekerja

Diperoleh sig $=0,000$ dan $\mathrm{t}$ hitung $=4,434>\mathrm{t}$ tabel 2,093, dan diperoleh juga $\mathrm{R}$ square 0,522 artinya variable secara varsial memiliki pengaruh yang signifikan terhadap variable terikat yaitu produktivitas pekerjaan dengan pekerjaa dinding Wallplus sebesar 52,2\%

d. Variable (X4) Kesehatan Pekerja

Diperoleh sig $=0,002$ dan $\mathrm{t}$ hitung $=3,587>\mathrm{t}$ tabel 2,093, dan diperoleh juga $\mathrm{R}$ square 0,417 artinya variable secara varsial memiliki pengaruh yang signifikan terhadap variable terikat yaitu produktivitas pekerjaan dengan pekerjaa dinding Wallplus sebesar $41,7 \%$

e. Variable (X5) Managerial

Diperoleh sig $=0,000$ dan $\mathrm{t}$ hitung $=4,459>\mathrm{t}$ tabel 2,093, dan diperoleh juga $\mathrm{R}$ square 0,525 artinya variable secara varsial memiliki pengaruh yang signifikan terhadap variable terikat yaitu produktivitas pekerjaan dengan pekerjaa dinding Wallplus sebesar 52,5\%

Jadi dengan demikian variabel managerial merupakan faktor paling dominan mempengaruhi besarnya produktivitas tenaga kerja secara signifikan pada pekerjaan dinding wallplus sebesar 52,5\%.

\section{Kesimpulan}

Dari hasil analisis yang dilakukan, maka dapat diambil kesimpulan yaitu sebagai berikut:

1. Besarnya tingkat produktivitas tenaga kerja pekerjaan dinding wallplus precast ringan pada proyek pembangunan `sekar jepun VI Denpasar Timur dapat diketahui produktivitas rata-rata yaitu 16,41 M2//Hari

2. Total Biaya Pelaksanaan pekerjaan dinding wallplus precast ringan pada masing-masing bangunan perumahan sekar jepun VI Denpasar Timur yaitu sebesar Rp. 19.773.256,80

3. Faktor Variabel Managerial mempunyai pengaruh yang dominan terhadap tingkat produktivitas tenaga kerja pada proyek pembangunan perumahan sekar jepun VI Denpasar Timur yaitu sebesar 52,5\%.

\section{Ucapan Terimakasih}

Penulis ingin menyampaikan terima kasih kepada Jurusan teknik Sipil Politeknik Negeri Bali yang membantu memfasilitasi penelitian, implementasi dan pelaporan penelitian.

\section{Daftar Rujukan}

[1]. Ilmu, K., 2013. Pengertian Sumber Daya Manusia. [Online]. Tersedia di: http://katailmu.com/2013/10/pengertian-danperanan-sumber-daya.html [Accessed 06 March 2018]

[2]. Malamassam, L., 2016. Analisis Produktivitas Pekerja Dengan Metode Time Study Pada Proyek Pembangunan Gdung Teknik Industri ITS. Surabaya: Institut Teknologi Sepuluh November.

[3]. Pengertian, S., 2016. Peningkatan Produktivitas. [Online] Tersedia di: http://seputarpengertian.blogspot.com/2016/08/pengertianproduktivitas-serta-sumbernya.html. [Accessed 11 March 2018]

[4]. Pratama, A., 2016. Analisis Tingkat Produktivitas Tenaga Kerja Terhadap Pekerjaan Struktur Proyek Pembangunan x. Denpasar: Politeknik Negeri Bali.

[5]. Secreat, F., 2011. Jenis-jenis Biaya Proyek. [Online]. Tersedia di: http://faiz-15.blogspot.com/2011/11/jenis-jenis-biayaproyek.html [Accessed 12 March 2018]

[6]. Susila, P. A., 2016. Analisis Tingkat Produktivitas Tenaga Kerja Pada Pekerjaan Rangka Atap Baja Ringan Proyek Pembangunan $x$. Denpasar: Politeknik Negeri Bali.

[7]. Teori, L., 2015. Pengertian Produktivitas Tenaga Kerja dan Faktor-faktor yang Mempengaruhi. [Online]. Tersedia di: http://www.landasanteori.com/2015/07/pengertian-kerjadan.html [Accessed 11 March 2018]

[8]. Wikipedia, 2017. Pengertian Dinding. [Online]. Tersedia di: https://id.m.wikipedia.org/wiki/Dinding. [Accesssed 11 March 2018] 